\title{
Fraktion DIE LINKE. im Deutschen Bundestag
}

\author{
Harald Koch, MdB \\ Mitglied im Unterausschuss Bürgerschaftliches Engagement für die \\ Bundestagsfraktion DIE LINKE. | harald.koch@bundestag.de \\ www.harald-koch-mdb.de $\mid$ www.linksfraktion.de
}

Wie bereits auf der Website www.voluntariszff.de zu lesen ist, soll Voluntaris-Zeitschrift für Freiwilligendienste eine wissenschaftlich orientierte Informations-, Diskussions- und Dokumentationsschrift für den Bereich Freiwilligendienste werden. Ziel ist, darin den Austausch zwischen akademischen und anwendungsbezogenen Perspektiven auf Freiwilligendienste zu fördern.

Damit ist nach dem Ausschlussprinzip schon einmal klar, was Voluntaris nicht sein will, nämlich eine Zeitschrift, die in erster Linie die Freiwilligen, die jungen Menschen mit ihren Erlebnissen zu Wort kommen lässt und ihnen hilfreiche Tipps mit auf den Weg gibt. Dennoch kann und sollte Voluntaris vor allem für Freiwilligendienstler, die sich vertiefend (!) mit ihrem Dienst und den darin vermittelten Inhalten beschäftigen wollen, eine gute Anlaufstelle bieten. Nur so gelingt schließlich der Sprung von der akademischen auf die anwendungsbezogene Perspektive, auf die Praxis. Und für Letztere muss man die Freiwilligen umfassend mit einbeziehen und ihre Wünsche, Erfahrungen und Anregungen ernst nehmen. Da es nicht nur eine Vielzahl von Freiwilligen, sondern eine Vielzahl von Freiwilligendiensten gibt, ist es aus meiner Sicht daher notwendig, jeden mit seinen ganz eigenen Spezifika in den Blick zu nehmen, das Besondere zu verdeutlichen und daran anknüpfend die speziellen Problemlagen offenzulegen und Lösungsansätze zu präsentieren.

Für DIE LINKE sind Freiwilligendienste Lern- und Bildungsdienste, dies sollte immer wieder hervorgehoben und auch in der Themenwahl der Zeitschrift Niederschlag finden. Grundlegend sollte die pädagogische Begleitung weiter gestärkt werden (dies auch als Petitum an uns PolitikerInnen). In diese Richtung könnte Voluntaris jedoch ebenfalls wirken, indem sie sich z. B. an der Konzeptentwicklung aus wissenschaftlicher Sicht beteiligt oder Seminare evaluiert und auswertet. Denn je nach Freiwilligendienst sind 
manche Dienste aus Sicht der Teilnehmenden klar unterpädagogisiert. Ferner wäre erforderlich, dass die Zeitschrift aufzeigt, dass Freiwilligendienste nur ein Teilbereich des bürgerschaftlichen Engagements sind. Welche Rolle Freiwilligendienste haben, ihre Besonderheiten im Vergleich zu anderen Engagementformen sollten herausgearbeitet werden.

An dieser Stelle kann ich nicht verhehlen, dass ich den Bundesfreiwilligendienst für überflüssig halte und lieber die rechtlichen Voraussetzungen geschaffen hätte, um die bestehenden Jugendfreiwilligendienste mithilfe erfahrener zivilgesellschaftlicher Akteure zu stärken - einen quasistaatlichen Dienst brauchen wir nicht. Die Zivilgesellschaft und ihre Akteure, gerade auch die kritischen und die nicht oder weniger organisierten, die sozialen Bewegungen (Freiwilligendienste bei sozialen NGOs etc.), sollten stärker in den Fokus rücken und ausreichend mitbetrachtet werden. Darüber hinaus kann es nicht schaden, interessierten Leserinnen und Lesern zu vermitteln, dass Freiwilligendienste nicht nur tolle Entwicklungsmöglichkeiten für junge Menschen bieten, wenn sie richtig ausgestaltet sind, sondern durchaus an manchen Stellen gesamtgesellschaftlich problematisch sein können. Hier sind Freiwilligendienste und bürgerschaftliches Engagement in das gesamte politische Umfeld einzubetten - auch eine Aufgabe einer wissenschaftlich orientierten Zeitschrift.

Die Bundesregierung muss diesbezüglich begreifen, dass eine nachhaltige Engagementpolitik mehr erfordert als steuerliche Erleichterungen (siehe Gemeinnützigkeitsentbürokratisierungsgesetz/Ehrenamtsstärkungsgesetz) und Bundesfreiwilligendienst. Dazu könnte Voluntaris beitragen, indem über den Tellerrand geblickt wird: Eine Zeitschrift für Freiwilligendienste in einer bunten, breit gefächerten Engagementwelt! So wird in Folge die Erwartungshaltung an die Freiwilligendienste und Absolventen nicht stetig erhöht. Freiwillige müssen sich mithin weniger als Lückenbüßer im Zuge der Schleifung sozialer Infrastruktur fühlen.

Weitere kritische und interessante Punkte, die auch in der Voluntaris nicht ausgespart, sondern offen und transparent behandelt werden sollten, sind:

- $\quad$ Arbeitsmarktneutralität - wird diese wirklich gewährleistet?

- Konkurrenz Bundesfreiwilligendienst - Jugendfreiwilligendienste

- Probleme mit der Altersöffnung im BFD für Über-27-Jährige? Auffangbecken für Erwerbslose und SeniorInnen? 
- $\quad$ Auswirkungen der Altersöffnung auf die Bildungsseminare

- Wer geht in den Bundesfreiwilligendienst - macht das Jobcenter Druck?

- Alle Freiwilligendienste unter ein „Ministerial-Dach“?

- Wird einem Niedrig,,lohn“sektor weiter Vorschub geleistet?

- $\quad$ Ersetzen diese Dienste soziale Infrastruktur? Ist eine Grenzziehung überhaupt möglich - und erwünscht?

- Bezüglich weltwärts: Erweiterung der Nord-Süd-Ausrichtung? Wie verbessert man den direkten interkulturellen Dialog auf Augenhöhe?

- Wie findet man bei weltwärts mehr lokale Partner in den Ländern des Südens, die zur sozialen Bewegung gehören und sich für Menschen- und andere soziale Rechte einsetzen?

- Wie kann die Ehemaligenarbeit verbessert werden?

$\mathrm{Zu}$ den von mir aufgeführten, aber gewiss gleichfalls zu vielen weiteren Punkten müsste sich jeder der drei zentralen Akteure eine fundierte Meinung bilden und Lösungskonzepte erarbeiten, die dann untereinander, sprich in der Zeitschrift, zu diskutieren sind. Bei diesem Trilog zwischen Praxis, Politik und Wissenschaft wird es darauf ankommen, dass man sich wirklich gegenseitig ,zuhört“, ernst nimmt und versucht, sich in die Perspektive des jeweils anderen einzufinden. Dann können sich die drei verschiedenen Perspektiven gegenseitig befruchten und Synergieeffekte zum Wohle der Freiwilligendienste bilden.

Als Wunsch bliebe mir, dass diese drei Akteure einen kritischen, jedoch konstruktiven und kreativen Geist beweisen. Dann wird Voluntaris mit Sicherheit dazu beitragen, Freiwilligendienste als Bildungs- und Lerndienste und damit als soziales Plus für junge Menschen zu stärken! 